\title{
A MULTICRITERIA APPROACH TO EVALUATE OFFSHORE WIND FARMS SITING IN GREECE
}

\section{D.G. VAGIONA* \\ N.M. KARANIKOLAS}

Received: 29/11/11

Accepted: 09/03/12

\author{
Aristotle University of Thessaloniki \\ Department of Spatial Planning and Development \\ Agia Varvara, Veria, 59100, Greece
}

*to whom all correspondence should be addressed: e-mail: dimvag@auth.gr

\begin{abstract}
Wind energy offers significant potential for greenhouse gas emissions reductions. Most applications have been developed onshore but the planning and siting conflicts with other land uses have created considerable interest and motivated research to offshore wind energy establishments.

In this paper, a systematic methodology in order to investigate the most efficient areas of offshore wind farms' siting in Greece is performed, integrating multi-criteria decision making (MCDM) methods and Geographic Information Systems (GIS) tools.

In the first level of analysis, all coastal areas that don't fulfill a certain set of criteria (wind velocity, protected areas, water depth) are identified with the use of Geographical Information Systems (GIS) and excluded from further analysis. The Analytical Hierarchy Process is performed in the evaluation phase and pairwise comparisons provide the most appropriate sites to locate offshore wind farms. Information concerning evaluation criteria (average wind velocity, distance to protected areas, distance to ship routes, distance to the shore and distance of possible connection to the existing electricity network) is retrieved through GIS, eliminating the subjectivity in judgments. The whole methodology contributes to the portrait of the geographic analysis and stands as the last image of the space characteristics suitable for offshore wind farms.
\end{abstract}

KEYWORDS: Analytical Hierarchy Process, Geographical Information Systems, offshore establishments, pairwise comparisons, renewable energy resources.

\section{INTRODUCTION}

Adoption of renewable energy technologies and promotion of green energy have internationally been recognized as a way towards independency from fuel oils. Green energy is provided by the natural environment and one of the most widely exploited and rapidly evolved types of renewable energy is the wind energy. Onshore wind energy technology is more mature than offshore, but nowadays, there is a considerable trend to the establishment of offshore wind farms. Although offshore wind farms present higher investment, operational and maintenance cost, the significant offshore wind resource potential, the higher quality wind resources located at sea, the ability to use even larger wind turbines due to avoidance of certain land and the ability of construction of even larger power plants than onshore, as there is no geographical "limit", form the primary motivations of developing offshore wind energy.

Europe has an abundant supply of energy in its waters that could contribute to the development of local economy and achievement of energy independence. The first offshore wind farm was built in 1991 in Denmark, consisting of 11 wind turbines (450 kW). Today, worldwide, ten out of 25 largest offshore wind farms in operation are located in United Kingdom, producing annually $1326 \mathrm{MW}$, while six of them are sited in Denmark reaching $705 \mathrm{MW}$. The rest offshore wind farms are situated in Belgium, Netherlands, Sweden, Finland, Ireland and Germany.

Although the construction of offshore wind farms has already been expanded in many European countries, this sector is quite underdeveloped in Greece. Up until now, there isn't any offshore wind 
farm under operation, while 37 studies are waiting for approval, three are in the stage of early planning and five have already been rejected.

The central aim of this work is to provide an integrated implementation of multicriteria analysis methods and GIS tools applications in order to select the most appropriate installation of offshore wind farms in Greece. Accordingly, the first part of this paper introduces the aspects related to the methodology, while the second illustrates the application of appropriate offshore wind farm siting in the study area, followed by a discussion of the results obtained from this analysis.

\section{MULTICRITERIA EVALUATION APPROACH AND GIS IN ENERGY RELATED ISSUES AND ENERGY PLANNING}

Energy and environmental issues are generally complex and conflict with multiple objectives. Multiple criteria decision making (MCDM) methods, which form one type of decision analysis methods, have been widely applied to analyze and formulate energy and environmental policies (Greening and Bernow 2004). Pohekar and Ramachandran (2004) reviewed more than 90 MCDM studies in sustainable energy planning. MCDM methods are classified into multiple objective decision making (MODM) and multiple attribute decision making (MADM) (Zhou et al., 2006). The last one (MADM) refers to making preference decisions by evaluating and setting priorities to all the alternatives.

Analytic hierarchy process (AHP) forms the most popular and easily performed MADM method, which is a methodology consisting of structuring, measurement and synthesis, contributing to help decision makers to cope with complex situations (Saaty, 1980). AHP (Akash et al., 1999; Chatzimouratidis and Pilavachi, 2007; 2008a; 2008b; 2009; Kablan, 2004; Mohsen and Akash, 1997) as well as pair-wise comparison (Mamlook et al., 2001; Wang et al., 2008a; 2008b) are known as the most frequently used subjective weighting methods (rank-order weights methods) in sustainable energy decision making. Different applications of AHP can be found and classified according to theme, including: selection, evaluation, benefit-cost analysis, allocations, planning and development, priority and ranking, and decision-making.

On the other hand, Geographic Information Systems (GIS) help the environmental industry to analyze, report, model, and map the merits of one site or location over another. The lack of geographic thinking can lead to problems when analysis is taking place. Many non-geographers, who work in environmental market, are capable of avoiding mistakes by taking into consideration some necessary geographic tools that GIS offers. It is known that the location is the most important parameter for environmental spatial analysis and location choice estimation can only be fully taken into account by using the descriptive framework of a geographic information system. The locations in a GIS can be determined very precisely in order to constitute the database of all parameters, which may have a big impact on choice's quality and estimation. An integrated GIS database consists of different basic geographical data layers involving networks, and digital elevation models (Din et al., 2001).

From identifying the best fit for new wind farm development or matching society decision criteria to managing energy needs, GIS brings the answers needed to make the best choice in environment. Today there are many GIS applications which deal with studies concerning wind energy implementation (Ramachandra and Shruthi, 2005; Aydin et al., 2010; Sliz-Szkliniarz and Vogt, 2011). With respect to wind energy policies, Dalton et al., argue that Denmark, among various successful measurements, used GIS based site selection tool in order to promote wind energy policies. They also underline the need to adopt similar measurements in Ireland, in order to supply premium locations sites for wave energy exploitation, which should include information concerning bathymetry, wave energy data, suitable port locations, nature reserves and many more (Dalton and Ó Gallachóir, 2010).

\section{Decision analysis using the AHP}

AHP has three underlying concepts, which include: a) structuring the complex decision problem as a hierarchy of goal, criteria and alternatives, b) pair-wise comparison of elements at each level of the hierarchy with respect to each criterion on the preceding level and c) vertically synthesizing the judgments over the different levels of the hierarchy (Saaty, 1980; Tiwari and Banerjee, 2001). The basic theory of AHP could be simplified as in the following (Saaty, 1980; Golden et al., 1989; Kablan, 2004): Assume that there are $n$ different and independent alternatives $\left(A_{1}, A_{2}, A_{n}\right)$ that they have the 
weights $\left(w_{1}, w_{2}, w_{n}\right)$, respectively. The decision maker is capable of making pair-wise comparison between the different alternatives in order to evaluate the values of the above weights. The quantified judgments are represented in an nxn matrix as in the following (Equation 1):

$$
A=\begin{array}{lllll}
A_{1} & A_{1} & A_{2} & \cdots & A_{n} \\
A_{2} & a_{11} & a_{12} & \cdots & a_{1 n} \\
a_{21} & a_{22} & \cdots & a_{2 n} \\
\cdot & \cdot & \cdot & \cdot \\
\cdot & \cdot & \cdot & \cdot \\
\cdot & A_{n} & \cdot & \cdot & \cdot \\
a_{n 1} & a_{n 2} & \cdot & a_{n n}
\end{array}
$$

The $a_{1 n}$ value indicates the relative importance of alternative $A_{1}$ to $A_{n}\left(w_{1} / w_{n}\right)$ and generalizing this relation, it can be concluded that $a_{i j}=w_{i} / w_{j}, i, j=1,2, \ldots, n$ and $a_{i i}=1, i, j=1,2, n$. Thus, the main diagonal in the matrix includes value of 1 and the decision maker has to provide value judgments in the upper triangle of the matrix. The entries below the diagonal are the reciprocal of those entries above the diagonal.

The relative importance assigned to $a_{i j}$ is usually provided by a nine value scale (1-9), where (1) indicates that $i$ is equally important to $j$, while (9) proves that $i$ is extremely more important than $j$.

In order to retrieve the numerical weights $\left(w_{1}, w_{2}, \ldots, w_{n}\right)$ of the alternatives (having recorded the numerical judgments $a_{i j}$ in the matrix $A$ ), the following equation is considered:

$$
\left(\begin{array}{llll}
a_{11} & a_{12} & \ldots & a_{1 n} \\
a_{21} & a_{22} & \ldots & a_{2 n} \\
\cdot & \cdot & \ldots & \cdot \\
\cdot & \cdot & \ldots & \cdot \\
a_{n 1} & a_{n 2} & \ldots & a_{n n}
\end{array}\right)=\left(\begin{array}{llll}
w_{1} / w_{1} & w_{1} / w_{2} & \ldots & w_{1} / w_{n} \\
w_{2} / w_{1} & w_{2} / w_{2} & \ldots & w_{2} / w_{n} \\
\cdot & \cdot & \ldots & \cdot \\
\cdot & \cdot & \ldots & \cdot \\
& & & \\
w_{n} / w_{1} & w_{n} / w_{2} & \ldots & w_{n} / w_{n}
\end{array}\right)
$$

By multiplying both matrices in equation 2 on the right with the weights vector $w=\left(w_{1}, w_{2}, \ldots, w_{n}\right)$, where $w$ is a column vector, a system of homogenous linear equations evokes. It has a non-trivial solution, if and only if, the determinant of $A-n l$, where I is an nxn identity matrix, vanishes (that is, $n$ is an eigenvalue of $A$ ). Saaty's method computes $w$, as the principal right eigenvector of the matrix $A$, that is, $A W=\lambda_{\max } W$, where $\lambda_{\max }$ is the principal eigenvalue of the matrix $A$. If matrix $A$ is a positive reciprocal one then $n \leq \lambda_{\max }$, (Saaty 1980). The judgments are perfectly consistent as long as $a_{i j} a_{j k}=a_{i k}, i, j, k=1,2, \ldots, n$, which is equivalent to $\left(w_{i} / w_{j}\right)\left(w_{j} / w_{k}\right)=\left(w_{i} / w_{k}\right)$ (Kablan 2004). The eigenvector method yields a natural measure of consistency. Saaty defined the consistency index $(\mathrm{Cl})$ as $\mathrm{Cl}=$ $\left(\lambda_{\max }-n\right) /(n-1)$ and consistency ratio $(C R)$ as $C R=C l / R I$, where $R I$ indicates the random index for corresponding matrix size and is given in Table 1.

Table 1. Average random index (Saaty, 1980)

\begin{tabular}{ccccccccccc}
\hline Matrix size $(\mathrm{n})$ & 1 & 2 & 3 & 4 & 5 & 6 & 7 & 8 & 9 & 10 \\
\hline Random index (RI) & 0 & 0 & 0.58 & 0.90 & 1.12 & 1.24 & 1.32 & 1.41 & 1.45 & 1.49 \\
\hline
\end{tabular}

\section{DECISION MAKING PROCESS FOR APPROPRIATE OFFSHORE WIND FARM SITING IN GREECE}

The decision making process followed in this work includes two main phases: (phase 1: exclusion phase, phase 2: evaluation phase).

All coastal areas and islands are candidates for selection. In the phase 1, three criteria of exclusion are implemented. Thus, areas that don't fulfill the minimum wind velocity $\left(6 \mathrm{~m} \mathrm{sec}^{-1}\right)$ for the operation of wind turbines, that are characterized as protected areas either by National or European legislation and that their sea depth exceeds 30 meters, are excluded from the analysis, using GIS techniques. Although, according to current Greek legislation, windfarms are allowed to be installed in regions which are classified as a protected site in the Natura 2000 network, in several cases, the opponents 
of specific wind-farm investment proposals have based their objections on the basis of the environmental impacts that the wind turbines are likely to cause (Dimitropoulos and Kontoleon, 2009). Water depth threshold reaches $30 \mathrm{~m}$, as for most offshore wind turbines installed through 2005 were less than $10 \mathrm{~m}$, but from 2006 to 2009, water depths from 10 to more than $20 \mathrm{~m}$ were common. Maps are superimposed and the remaining empty zones are considered as the areas that could possibly welcome new infrastructures. The process followed in phase 1 can be formed to figure 1.

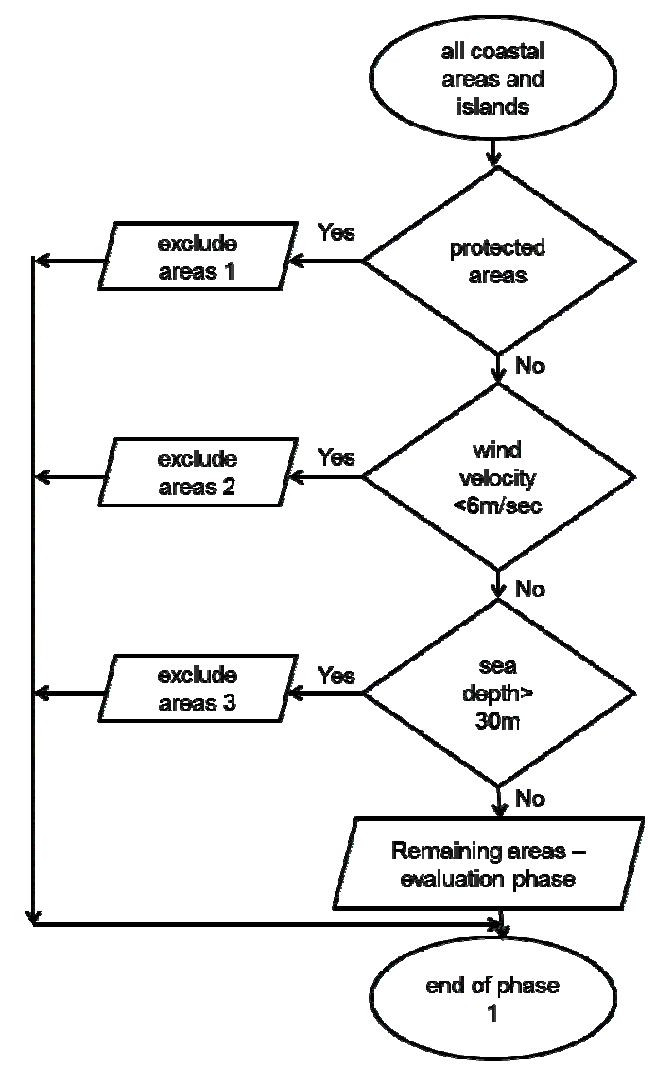

Figure 1. MCDA process phase 1

Level 1: Goal

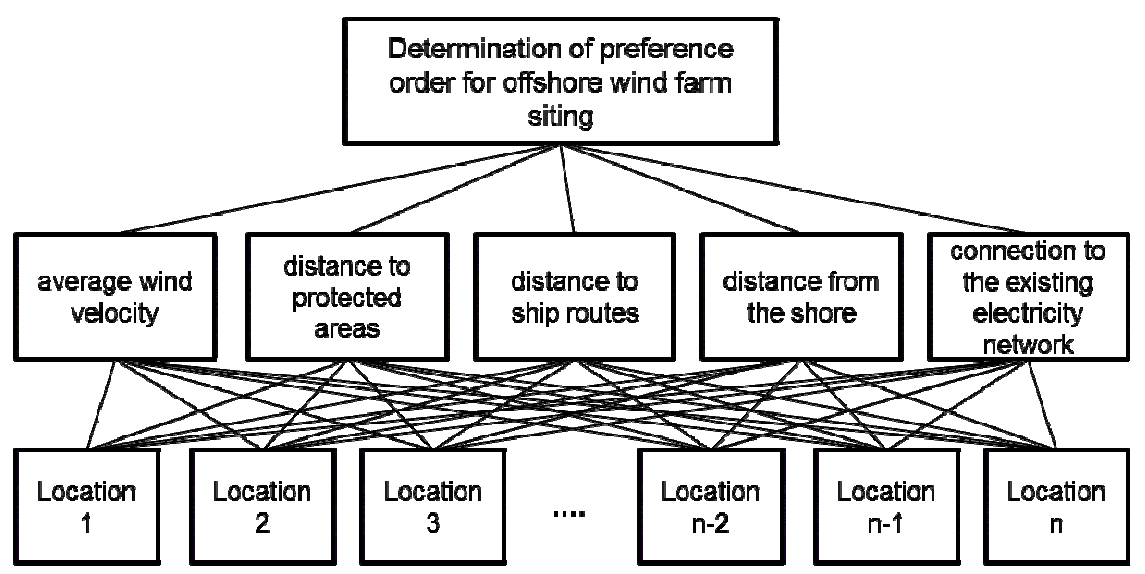

Figure 2. Hierarchy tree of MCDA process phase 2

Decision making process in the next phase includes: alternatives' formulation and criteria selection, criteria weighting, evaluation and final treatment and aggregation. Thus, in the second phase of the analysis, decision - making process is divided in hierarchical terms in three parts (Figure 2): goal (proper offshore wind farm selection), evaluation criteria (average wind velocity, distance to protected areas, distance to ship routes, distance from the shore and possibility of connection to the existing electricity network) and alternatives (all areas not excluded in the first phase). 
AHP method is based on the pair-wise comparison method in order to determine the weights for every unique criteria. In the pair-wise comparison method, the importance of two criteria at a time is asked and the relative importance is scored. The basic question applied has the form: "Which one of these two criteria is more important and how much more or less important?" and thus a matrix of pairwise comparisons is created. The matrices of judgments corresponding to the pairwise comparison of evaluation criteria at the second level of the hierarchy are based on the authors' expertise and experience. Of course, in order to minimize the subjectivity, a group of policy makers should set together in a brainstorming session and arrive at a consensus about each of these subjective value judgments. At the third level of analysis, the judgments are accurate, as they are generated with the aid of GIS.

Features of the evaluation criteria in the second level of AHP are presented in Table 2.

Table 2. Metadata of evaluation criteria

\begin{tabular}{lcll}
\hline \multicolumn{1}{c}{ Criteria } & Type & \multicolumn{1}{c}{ Description } & \multicolumn{1}{c}{$\begin{array}{c}\text { Unit of } \\
\text { measurement } \\
\mathrm{m} \mathrm{sec}^{-1}\end{array}$} \\
$\begin{array}{l}\text { Average wind velocity } \\
\text { (WS) }\end{array}$ & Quantitative & the average speed of wind & \\
$\begin{array}{l}\text { Distance to protected areas } \\
\text { (DPA) }\end{array}$ & Quantitative & $\begin{array}{l}\text { distance from - to protected } \\
\text { areas }\end{array}$ & $\mathrm{km}$ \\
$\begin{array}{l}\text { Distance to ship routes } \\
\text { (DSR) }\end{array}$ & Quantitative & $\begin{array}{l}\text { the distance from the bed to } \\
\text { the surface of the see }\end{array}$ & $\mathrm{km}$ \\
$\begin{array}{l}\text { Distance from the shore } \\
\text { (DS) }\end{array}$ & Quantitative & $\begin{array}{l}\text { the distance of the possible } \\
\text { location to the shore }\end{array}$ & $\mathrm{km}$ \\
$\begin{array}{l}\text { Connection to the electricity } \\
\text { network } \\
\text { (CEN) }\end{array}$ & Quantitative & $\begin{array}{l}\text { feasibility of connection to } \\
\text { electricity network }\end{array}$ & $\mathrm{km}$ \\
\hline
\end{tabular}

\section{RESULTS}

\section{Exclusion phase - phase 1}

In Figure 3, 4 and 5 the three exclusion criteria are presented and in Figure 6 the candidate areas for the second phase evoke, after the overlapping of the three maps.

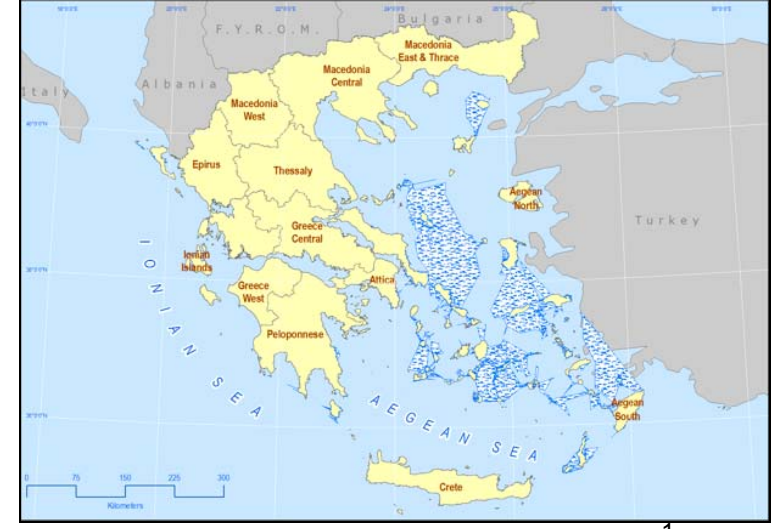

Figure 3 . Wind velocity $>6 \mathrm{~m} \mathrm{sec}^{-1}$

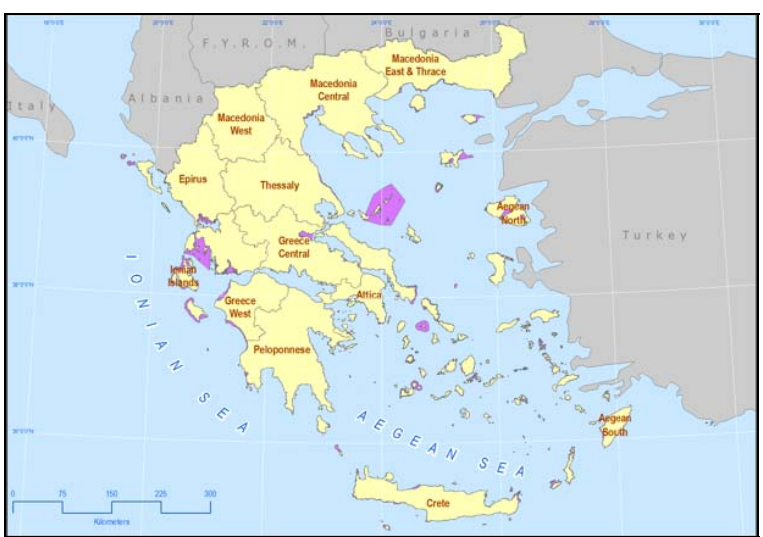

Figure 4. Depiction of protected areas

\section{Evaluation Phase (Phase 2)}

The matrices of judgements to pair-wise comparisons of elements at each level of the hierarchy are generated. Table 3 presents the matrix of pair-wise comparisons between the different criteria in level two of the hierarchy with respect to goal. 


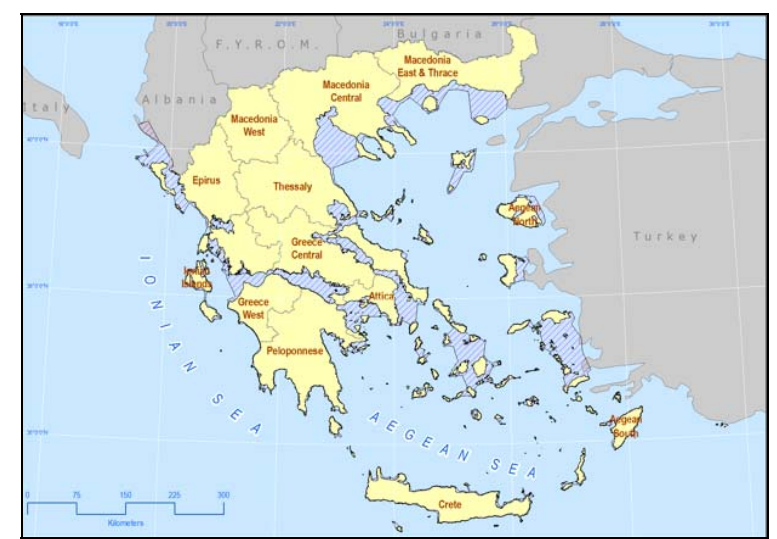

Figure 5. Sea depth $<30 \mathrm{~m}$

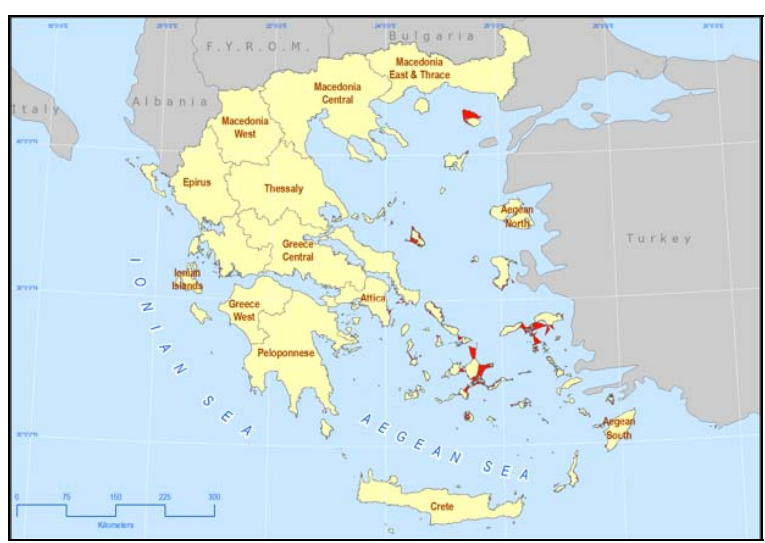

Figure 6. Candidate zones

Table 3. Pairwise comparison of criteria with respect to goal

\begin{tabular}{cccccc}
\hline & WS & DPA & DSR & DS & CEN \\
\hline WS & 1 & $1 / 5$ & 3 & $1 / 5$ & $1 / 7$ \\
DPA & 5 & 1 & 5 & $1 / 3$ & $1 / 3$ \\
DSR & $1 / 3$ & $1 / 5$ & 1 & $1 / 7$ & $1 / 9$ \\
DS & 5 & 3 & 7 & 1 & $1 / 3$ \\
CEN & 7 & 3 & 9 & 3 & 1 \\
\hline
\end{tabular}

A local priority vector can be generated for the matrix of judgements, by dividing each entry of the column by the column sum (normalizing the vector in each column) and averaging over the rows of the resulting matrix (Table 4).

Table 4. Priority vector of criteria

\begin{tabular}{ccccccc}
\hline & WS & DPA & DSR & DS & CEN & priority vector \\
\hline WS & 0.055 & 0.027 & 0.120 & 0.043 & 0.074 & 0.064 \\
DPA & 0.273 & 0.135 & 0.200 & 0.071 & 0.174 & 0.171 \\
DSR & 0.018 & 0.027 & 0.040 & 0.031 & 0.058 & 0.035 \\
DS & 0.273 & 0.405 & 0.280 & 0.214 & 0.174 & 0.269 \\
CEN & 0.382 & 0.405 & 0.360 & 0.642 & 0.521 & 0.462 \\
\hline
\end{tabular}

Table 5. Pairwise comparison of possible locations with respect to criteria WS $(\mathrm{CR}=0.052)$

\begin{tabular}{llllllllllll}
\hline & L1 & L2 & L3 & L4 & L5 & L6 & L7 & L8 & L9 & L10 & $\begin{array}{c}\text { priority } \\
\text { vector }\end{array}$ \\
\hline Kassos (L1) & 1 & 1 & $1 / 2$ & $1 / 7$ & $1 / 2$ & $1 / 3$ & 2 & 3 & 7 & 3 & 0.069 \\
Karpathos (L2) & 1 & 1 & $1 / 2$ & $1 / 7$ & 0,5 & $1 / 3$ & 2 & 3 & 7 & 3 & 0.069 \\
Amorgos (L3) & 2 & 2 & 1 & $1 / 5$ & 1 & $1 / 2$ & 3 & 4 & 8 & 4 & 0.107 \\
Anafi (L4) & 7 & 7 & 5 & 1 & 5 & 4 & 7 & 8 & 9 & 8 & 0.361 \\
Andros (L5) & 2 & 2 & 1 & $1 / 5$ & 1 & $1 / 2$ & 3 & 4 & 8 & 4 & 0.107 \\
Skyros (L6) & 3 & 3 & 2 & $1 / 4$ & 2 & 1 & 4 & 5 & 8 & 5 & 0.156 \\
Samothraki (L7) & $1 / 2$ & $1 / 2$ & $1 / 3$ & $1 / 7$ & $1 / 3$ & $1 / 4$ & 1 & 3 & 7 & 3 & 0.055 \\
Rhodes (L8) & $1 / 3$ & $1 / 3$ & $1 / 4$ & $1 / 8$ & $1 / 4$ & $1 / 5$ & $1 / 3$ & 1 & 5 & 1 & 0.032 \\
Kos (L9) & $1 / 7$ & $1 / 7$ & $1 / 8$ & $1 / 9$ & $1 / 8$ & $1 / 8$ & $1 / 7$ & $1 / 5$ & 1 & $1 / 5$ & 0.014 \\
Othonoi (L10) & $1 / 3$ & $1 / 3$ & $1 / 4$ & $1 / 8$ & $1 / 4$ & $1 / 5$ & $1 / 3$ & 1 & 5 & 1 & 0.032 \\
\hline
\end{tabular}


Table 6. Pairwise comparison of possible locations with respect to criteria DPA $(C R=0.028)$

\begin{tabular}{llllllllllll}
\hline & L1 & L2 & L3 & L4 & L5 & L6 & L7 & L8 & L9 & L10 & vector \\
\hline Kassos (L1) & 1 & $1 / 5$ & $1 / 3$ & $1 / 9$ & 1 & $1 / 5$ & 1 & $1 / 2$ & $1 / 7$ & $1 / 2$ & 0.024 \\
Karpathos (L2) & 5 & 1 & 3 & $1 / 5$ & 5 & 1 & 5 & 4 & $1 / 3$ & 4 & 0.117 \\
Amorgos (L3) & 3 & $1 / 3$ & 1 & $1 / 7$ & 3 & $1 / 3$ & 3 & 2 & $1 / 5$ & 2 & 0.059 \\
Anafi (L4) & 9 & 5 & 7 & 1 & 9 & 5 & 9 & 8 & 3 & 8 & 0.348 \\
Andros (L5) & 1 & $1 / 5$ & $1 / 3$ & $1 / 9$ & 1 & $1 / 5$ & 1 & $1 / 2$ & $1 / 7$ & $1 / 2$ & 0.024 \\
Skyros (L6) & 5 & 1 & 3 & $1 / 5$ & 5 & 1 & 5 & 4 & $1 / 3$ & 4 & 0.117 \\
Samothraki (L7) & 1 & $1 / 5$ & $1 / 3$ & $1 / 9$ & 1 & $1 / 5$ & 1 & $1 / 2$ & $1 / 7$ & $1 / 2$ & 0.024 \\
Rhodes (L8) & 2 & $1 / 4$ & $1 / 2$ & $1 / 8$ & 2 & $1 / 8$ & 2 & 1 & $1 / 6$ & 1 & 0.039 \\
Kos (L9) & 7 & 3 & 5 & $1 / 3$ & 7 & 3 & 7 & 6 & 1 & 6 & 0.210 \\
Othonoi (L10) & 2 & $1 / 4$ & $1 / 2$ & $1 / 8$ & 2 & $1 / 4$ & 2 & 1 & $1 / 6$ & 1 & 0.039 \\
\hline
\end{tabular}

Table 7. Pairwise comparison of possible locations with respect to criteria DSR $(C R=0.028)$

\begin{tabular}{llllllllllll}
\hline & L1 & L2 & L3 & L4 & L5 & L6 & L7 & L8 & L9 & L10 & $\begin{array}{l}\text { priority } \\
\text { vector }\end{array}$ \\
\hline Kassos (L1) & 1 & $1 / 5$ & 1 & $1 / 3$ & $1 / 5$ & $1 / 3$ & $1 / 5$ & $1 / 3$ & 1 & 3 & 0.038 \\
Karpathos (L2) & 5 & 1 & 5 & 3 & 1 & 1 & 1 & 3 & 5 & 7 & 0.179 \\
Amorgos (L3) & 1 & $1 / 5$ & 1 & $1 / 3$ & $1 / 5$ & $1 / 5$ & $1 / 5$ & $1 / 3$ & 1 & 3 & 0.036 \\
Anafi (L4) & 3 & $1 / 3$ & 3 & 1 & $1 / 3$ & $1 / 3$ & $1 / 3$ & 1 & 3 & 5 & 0.079 \\
Andros (L5) & 5 & 1 & 5 & 3 & 1 & 1 & 1 & 3 & 5 & 7 & 0.179 \\
Skyros (L6) & 5 & 1 & 5 & 3 & 1 & 1 & 1 & 3 & 5 & 7 & 0.179 \\
Samothraki (L7) & 5 & 1 & 5 & 3 & 1 & 1 & 1 & 3 & 5 & 7 & 0.179 \\
Rhodes (L8) & 3 & $1 / 3$ & 3 & 1 & $1 / 3$ & $1 / 3$ & $1 / 3$ & 1 & 3 & 5 & 0.079 \\
Kos (L9) & 1 & $1 / 5$ & 1 & $1 / 3$ & $1 / 5$ & $1 / 5$ & $1 / 5$ & $1 / 3$ & 1 & 3 & 0.036 \\
Othonoi (L10) & $1 / 3$ & $1 / 7$ & $1 / 3$ & $1 / 5$ & $1 / 7$ & $1 / 7$ & $1 / 7$ & $1 / 5$ & $1 / 3$ & 1 & 0.019 \\
\hline
\end{tabular}

Table 8. Pairwise comparison of possible locations with respect to criteria DS

\begin{tabular}{llllllllllll}
\multicolumn{10}{c}{$(\mathrm{c}=0.012)$} \\
\hline & L1 & L2 & L3 & L4 & L5 & L6 & L7 & L8 & L9 & L10 & $\begin{array}{c}\text { priority } \\
\text { vector }\end{array}$ \\
\hline Kassos (L1) & 1 & 1 & 1 & $1 / 7$ & 1 & 1 & 1 & $1 / 3$ & $1 / 3$ & $1 / 5$ & 0.039 \\
Karpathos (L2) & 1 & 1 & 1 & $1 / 7$ & 1 & 1 & 1 & $1 / 3$ & $1 / 3$ & $1 / 5$ & 0.039 \\
Amorgos (L3) & 1 & 1 & 1 & $1 / 7$ & 1 & 1 & 1 & $1 / 3$ & $1 / 3$ & $1 / 5$ & 0.039 \\
Anafi (L4) & 7 & 7 & 7 & 1 & 7 & 7 & 7 & 5 & 5 & 3 & 0.348 \\
Andros (L5) & 1 & 1 & 1 & $1 / 7$ & 1 & 1 & 1 & $1 / 3$ & $1 / 3$ & $1 / 5$ & 0.039 \\
Skyros (L6) & 1 & 1 & 1 & $1 / 7$ & 1 & 1 & 1 & $1 / 3$ & $1 / 3$ & $1 / 5$ & 0.039 \\
Samothraki (L7) & 1 & 1 & 1 & $1 / 7$ & 1 & 1 & 1 & $1 / 3$ & $1 / 3$ & $1 / 5$ & 0.039 \\
Rhodes (L8) & 3 & 3 & 3 & $1 / 5$ & 3 & 3 & 3 & 1 & 1 & $1 / 3$ & 0.105 \\
Kos (L9) & 3 & 3 & 3 & $1 / 5$ & 3 & 3 & 3 & 1 & 1 & $1 / 3$ & 0.105 \\
Othonoi (L10) & 5 & 5 & 5 & $1 / 3$ & 5 & 5 & 5 & 3 & 3 & 1 & 0.205 \\
\hline
\end{tabular}

The consistency of judgements is tested, by calculating $\mathrm{CR}=0.07$ and as it is below $10 \%$, the judgements are considered consistent.

In the next step of phase 2, the composite priorities of the alternatives are determined by aggregating the weights throughout the hierarchy. Tables $5-9$ provide the pairwise comparison matrices of the potential siting of offshore windfarm locations (alternatives in the second level of the 
hierarchy with respect to each criterion separately in the previous level). All judgements are performed according to data retrieved from the GIS. More specifically the average wind speed data $(\mathrm{m} / \mathrm{sec})$ evokes for every location by applying the map of wind potential, and distances $(\mathrm{km})$ i) to protected areas, ii) to the closest ship route, iii) to the shore and iv) to the closest possible point of electricity connection are calculated.

Table 9. Pairwise comparison of possible locations with respect to criteria CEN $(C R=0.03)$

\begin{tabular}{llllllllllll}
\hline & L1 & L2 & L3 & L4 & L5 & L6 & L7 & L8 & L9 & L10 & $\begin{array}{l}\text { priority } \\
\text { vector }\end{array}$ \\
\hline Kassos (L1) & 1 & $1 / 5$ & $1 / 5$ & 5 & $1 / 3$ & 3 & $1 / 5$ & $1 / 3$ & $1 / 3$ & 1 & 0.043 \\
Karpathos (L2) & 5 & 1 & 1 & 9 & 3 & 7 & 1 & 3 & 3 & 5 & 0.202 \\
Amorgos (L3) & 5 & 1 & 1 & 9 & 3 & 7 & 1 & 3 & 3 & 5 & 0.202 \\
Anafi (L4) & $1 / 5$ & $1 / 9$ & $1 / 9$ & 1 & $1 / 7$ & $1 / 3$ & $1 / 9$ & $1 / 7$ & $1 / 7$ & $1 / 5$ & 0.014 \\
Andros (L5) & 3 & $1 / 3$ & $1 / 3$ & 7 & 1 & 5 & $1 / 3$ & 1 & 1 & 3 & 0.090 \\
Skyros (L6) & $1 / 3$ & $1 / 7$ & $1 / 7$ & 3 & $1 / 5$ & 1 & $1 / 7$ & $1 / 5$ & $1 / 5$ & $1 / 3$ & 0.023 \\
Samothraki (L7) & 5 & 1 & 1 & 9 & 3 & 7 & 1 & 3 & 3 & 5 & 0.202 \\
Rhodes (L8) & 3 & $1 / 3$ & $1 / 3$ & 7 & 1 & 5 & $1 / 3$ & 1 & 1 & 3 & 0.090 \\
Kos (L9) & 3 & $1 / 3$ & $1 / 3$ & 7 & 1 & 5 & $1 / 3$ & 1 & 1 & 3 & 0.090 \\
Othonoi (L10) & 1 & $1 / 5$ & $1 / 5$ & 5 & $1 / 3$ & 3 & $1 / 5$ & $1 / 3$ & $1 / 3$ & 1 & 0.043 \\
\hline
\end{tabular}

The results of the prioritization process are provided by the composite weights for the possible offshore windfarms siting and presented in Table 10.

Table 10. Final prioritization of windfarms siting

\begin{tabular}{llll}
\hline Kassos (L1) & 0.040 & Skyros (L6) & 0.057 \\
\hline Karpathos (L2) & 0.134 & Samothraki (L7) & 0.118 \\
\hline Amorgos (L3) & 0.122 & Rhodes (L8) & 0.081 \\
\hline Anafi (L4) & 0.185 & Kos (L9) & 0.108 \\
\hline Andros (L5) & 0.069 & Othonoi (L10) & 0.084 \\
\hline
\end{tabular}

\section{CONCLUSIONS}

The issue of siting of various projects-establishments forms the initial reflection in environmental impact assessment and planning. The need of maximum exploitation of wind resources potential along with the concern to the environmental protection requires the fulfilment of various constraints and criteria. GIS applications contribute to the exclusion of sites that don't satisfy certain criteria. Additionally, the above tool offers information related to spatial characteristics, geographical features and environmental components of areas under study. The production of thematic maps, can be used in order to monitor phenomena as well as define which locations have a comparative advantage towards others. AHP method is becoming in the rank-order weighting method more and more prevalent because of its understandability in theory and simplicity in application and is used in order to hierarchically rank possible offshore wind farm locations.

This approach has attempted to select the ten most appropriate sites for offshore wind farm siting among the numerous choices that a country like Greece offers. Anafi, Karpathos and Amorgos are considered the three top choices of windfarm siting. All these areas present average wind speed up to $10 \mathrm{~m} / \mathrm{sec}$ and especially Anafi offers a really enormous surface of up to $300 \mathrm{~km}^{2}$ that could be exploited for wind energy plants.

As experience is gained, water depths are expected to increase further and more exposed locations with higher winds will be utilized. These trends will impact the exclusion criteria of water depth, increase its value, including even much more areas in the evaluation phase. The methodology followed in this study can easily be adapted to such changes regarding either exclusion or evaluation criteria. This work proves the soundness and strength of multicriteria analysis as a means to serve energy planners as an unambiguous tool for decision making and should be used before initiating any environmental impact assessment study for a given location. 


\section{REFERENCES}

Akash B.A., Mamlook R., Mohsen M.S., (1999) Multi-criteria selection of electric power plants using analytical hierarchy process, Electric Power Systems Research, 52, 29-35.

Aras H., Erdogmus S., Ko E., (2004) Multi-criteria selection for a wind observation station location using analytic hierarchy process, Renewable Energy, 29, 1383-92.

Aydin N.Y., Kentel E. and Duzgun S., (2010) GIS-based environmental assessment of wind energy systems for spatial planning: A case study from Western Turkey, Renewable and Sustainable Energy Reviews, 14(1), 364-373.

Chatzimouratidis A.I. and Pilavachi P.A., (2007) Objective and subjective evaluation of power plants and their non-radioactive emissions using the analytic hierarchy process, Energy Policy, 35, 4027-38.

Chatzimouratidis A.I. and Pilavachi P.A., (2008a) Multicriteria evaluation of power plants impact on the living standard using the analytic hierarchy process, Energy Policy, 36, 1074-89.

Chatzimouratidis A.I. and Pilavachi P.A., (2008b) Sensitivity analysis of the evaluation of power plants impact on the living standard using the analytic hierarchy process, Energy Conversion and Management, 49, 3599-611.

Chatzimouratidis A.I. and Pilavachi P.A., (2009) Technological, economic and sustainability evaluation of power plants using the Analytic Hierarchy Process, Energy Policy, 37, 778-87.

Dalton G. and Ó Gallachóir B., (2010) Building a wave energy policy focusing on innovation, manufacturing and deployment, Renewable and Sustainable Energy Reviews, 14(8), 2339-2358.

Dimitropoulos A. and Kontoleon A., (2009) Assessing the determinants of local acceptability ofwind farm investment: A choice experiment in the Greek Aegean Islands, Energy Policy, 37, 1842 - 1854.

Din A., Hoesli M. and Bender A., (2001) Environmental Variables and Real Estate Prices. Urban Studies, 38, 1989-2000.

Greening L.A. and Bernow S., (2004) Design of coordinated energy and environmental policies: use of multi-criteria decision-making, Energy Policy, 32, 721-35.

Golden B.L., Wasil E.A. and Harker P.T., (1989) The analytic Hierarchy Process, Springer, Berlin, Heidelberg.

Kablan M.M., (2004) Decision support for energy conservation promotion: an analytic hierarchy process approach, Energy Policy, 32, 1151-8.

Mamlook R., Akash B.A. and Nijmeh S., (2001) Fuzzy sets programming to perform evaluation of solar systems in Jordan, Energy Conversion and Management, 42, 1717-26.

Mohsen M.S. and Akash B.A., (1997) Evaluation of domestic solar water heating system in Jordan using analytic hierarchy process, Energy Conversion and Management, 38, 1815-22.

Pohekar S.D. and Ramachandran M., (2004) Application of multi-criteria decision making to sustainable energy planning - a review, Renewable Sustainable Energy Review, 8, 365-81.

Ramachandra T. and Shruthi B., (2005) Wind energy potential mapping in Karnataka, India, using GIS, Energy Conversion and Management, 46(9-10), 1561-1578.

Saaty T.L., (1980) The analytic hierarchy process, New York, McGraw-Hill.

Sliz-Szkliniarz B. and Vogt J., (2011) GIS-based approach for the evaluation of wind energy potential: A case study for the Kujawsko-Pomorskie Voivodeship, Renewable and Sustainable Energy Reviews, 15(3), 1696-1707.

Tiwari M.K. and Banerjee R., (2001) A decision support system for the selection of a casting process using analytic hierarchy process, Production Planning \& Control, 12(7), 689-694.

Wang J.J., Jing Y.Y., Zhang C.F., Shi G.H. and Zhang X.T., (2008a) A fuzzy multi-criteria decisionmaking model for trigeneration system, Energy Policy, 36, 3823-32.

Wang J.J., Zhang C.F., Jing Y.Y. and Zheng G.Z., (2008b) Using the fuzzy multi-criteria model to select the optimal cool storage system for air conditioning, Energy and Buildings, 40, 2059-66.

Xu J.P. and Wu W., (2006) Multiple attribute decision making theory and methods, Beijing, Tsinghua University Press.

Zhou P., Ang B.W. and Poh K.L., (2006) Decision analysis in energy and environmental modeling: An update, Energy, 31, 2604-2622. 